\title{
Technical approach in the education system
}

\author{
Yarash Gaffarov ${ }^{1}$ \\ ${ }^{1}$ Chirchik State Pedagogical Institute, Associate Professor, Uzbekistan
}

Email:_gafforov_ya@umail.uz

\begin{abstract}
At present, as in all areas in the educational system, peculiar innovations are applied. In particular, to find a technological approach in the education system, to increase the effectiveness of training, and also to use new pedagogical technologies, the learning process become our main tasks. For the use of new pedagogical and information technologies, their analysis and theoretical generalization, to present to students becomes one of the important problems.
\end{abstract}

Keywords: education, educational system, innovation, technological approach, pedagogical technologies, learning process.

\section{INTRODUCTION}

The development of pedagogical technologies, their critical analysis of the theoretical foundations depends on an effective approach to the learning process. That is, with the naming of the theoretical foundations of pedagogical technologies, it is possible to change its "problem area". Criticizing the technological approach in the education system requires solving a number of didactic problems[1,p.171]. In particular, to develop a list of didactic more complete, in connection with them to design the learning process, ensure the integrity of the learning process and the phased correspondence between them, learn the full social experience of students, achieve equalization of knowledge, skills and others.

\section{MAIN PART}

It is known that any pedagogical technology is a developing area in the education system and must certainly educate the teaching person. In the center of the theory of pedagogical technology in the learning process is a leader. At this time, teachers and students are considered both the subject and object of this process. Mutual cooperation, mutual communication, their influence reflecting on each other should meet modern requirements. For this, the teacher must first of all be able to organize and control the learning and upbringing process, develop the student both mentally and physically, work with him, guide him in the right way for learning, organize the activities of the teaching person, be in communication with him, be able to solve problems arising in the process of pedagogical activity, organize a creative atmosphere in the audience, create methods for the correct assessment of student activity[2,p.189]. The role of modern pedagogical methods, interactive methods, and innovative technologies in higher education institutions, faculties in the training of qualified personnel is very large. Educational technology and interactive methods ensure students become highly skilled.

Innovative technology in the pedagogical process is considered an innovation for the teacher and student, and interactive methods are used for its implementation.

Interactive methods are conducted by collective thinking, that is, the techniques and methods of pedagogy are an integral part of the content of the learning process. A feature of this method is the collective work of a teacher with students. Such pedagogical cooperation has its own property, which includes:

1. During the lesson, the student should be able to independently think, conduct creative and research work.

2. In the learning process, provide the student with a constant increase in interest in knowledge.

3. To teach the student to find a creative approach to each issue.

4. Organize ongoing cooperation between teachers and students. 
Currently, education is becoming an active area[3,p.147].

It is known that today there are many pedagogical technologies and their scientific research used in the learning process. Of course, these scientific views do not contradict each other, but complement each other.

If you look into the past, the term "pedagogical technology" entered the subject of Western pedagogy in the 1950-60s. Scientists have made many definitions, clarifications and notes on pedagogical technologies. Some teachers of practice consider highlighting interactive methods and a means of teaching pedagogical technologies. In order not to have a wrong concept among students, you need to be able to distinguish ped technology from teaching methods.

Currently, teachers, educators and psychologists are working to improve the effectiveness of educational technologies and provide us with the opportunity to have a vivid idea of this process.

Along with didactic technologies, pedagogical technologies have their own main directions. It:

One general and integral direction. It consists of two aspects:

- unity of personality development in education and upbringing.

- A rigorous system of pedagogical technologies, the concept of "systemicity".

Each teacher should organize a learning process based on these aspects. Studied the talents and capabilities of students, teachers should work only authoritarian, but work on the basis of humane ideas of cooperation in education. In turn, this leads to the development of a highly spiritual personality[4,p.244].

\section{CONCLUSION}

The direction of teaching-research, research-teaching. This direction is divided into two aspects: firstly, each teacher of a higher educational institution should have attract students to his field of activity and conduct active research.

Secondly, the teacher must develop technological teaching methods and introduce changes during the test process; these two aspects in the learning process are important, it makes it possible to improve the professional and pedagogical skills of the teacher, and prepare future specialists in their field of activity.

Thus, in the conditions of independence, the Republic of Uzbekistan activates new pedagogical technologies in the learning process by leading organizations. In particular, AXELS, IREX, JICA and KOICA are distinguished by their effective activity. In recent years $k$ with the help of the above organizations, innovation centers at higher educational institutions were organized in the Republic. On the part of the above-mentioned centers, scientific seminars, short and long-term courses were created, where teachers from higher educational institutions, academic lyceums, professional colleges, and general secondary schools participated, and gained knowledge and skills in using the theory and practice of pedagogical technologies in the learning process.

\section{ACKNOWLODGEMENT}

We hereby say thank you to Chirchik State Pedagogical Institute for supporting our research.

\section{REFERENCES}

1. Azizkhojaeva N.N. Pedagogical technologies and pedagogical skills.-Tashkent, 2006.

2. Gaffarov Y.X. Ways to use new pedagogical technologies in teaching special subjects. Tashkent, 2008.

3. Yuldashev JF, Usmanov SA Fundamentals of pedagogical technology Tashkent, 2004.

4. Saidahmedov N. New pedagogical technologies. - Tashkent: Finance 2003. 